Remarks by World Bank Group President David Malpass at the One Planet Summit

January 11, 2021

\title{
Opening Remarks at the One Planet Summit on Biodiversity
}

President Macron, Secretary Guterres, Your Royal Highness, Excellencies.

I am very pleased to co-convene this year's One Planet Summit, just as the World Bank Group did in 2017 in Paris, 2018 in New York, and 2019 in Nairobi. Thank you, President Macron, for your leadership and commitment to the climate and biodiversity agenda.

Climate change and the loss of biodiversity are defining issues of our time. They present critical challenges to our development efforts, including reducing poverty and inequality.

This year presents many opportunities for countries to align their biodiversity and climate goals with development programs, including COP15 in Kunming and COP26 in Glasgow in November.

It's important that we support developing countries in achieving their NDCs, helping them develop long term strategies for low-carbon and climate-resilient economies, end their reliance on coal, and address biodiversity loss.

The World Bank Group is the biggest multilateral funder of climate investments in developing countries, with record commitments last fiscal year. We intend to go further. Last month, I announced an ambitious target from the World Bank Group for $35 \%$ of our financing to have climate co-benefits, on average, over the next five years. This will help countries rebuild greener and with more resilience, for instance through low-carbon infrastructure and more environmentally friendly agriculture practices. We will also maintain a strong emphasis on climate adaptation with the goal of it accounting for at least $50 \%$ of World Bank climate finance.

In addition, the World Bank Group has supported operations focused on biodiversity conservation for three decades - conserving species and natural habitats and working to improve livelihoods for people in sectors that rely on natural capital, including forestry, fisheries, and agriculture. We will continue to ramp up our biodiversity work and the sustainable management of terrestrial, coastal, and marine ecosystems.

Over the last two years, we have supported the creation and consolidation of more than 100 million hectares of Marine and Coastal Protected Areas along with 10 million hectares of terrestrial protected areas in Asia, Africa, and Latin America.

In India, our operations supported mapping the entire coastline and planting 16,500 hectares of mangroves that offer protection during extreme weather. All of this helps improve the coastal livelihoods of 1.7 million people. Almost all of our new lending in China is toward global public goods, including the reduction of marine plastics. In West Africa, our program is fighting coastal erosion, bringing back livelihoods. 
And as you'll hear later, we're scaling up our support to restore degraded land across Africa's drylands in the Sahel, Lake Chad, and Horn of Africa regions. COVID-19 has shown the linkages between human and planetary health. With Germany's support, we are doing new research into the investments and policies that will help to drive the "One Health" approach to preventing emerging infectious diseases.

As countries build back, we must work together - the private sector, civil society, governments, institutions like our own, and communities - to support a green, inclusive, and resilient recovery.

It's very clear: we cannot succeed in helping countries reduce poverty and inequality without rising to the challenges of climate change and the loss of biodiversity. Thank you.

\section{Remarks at the One Planet Summit Agroecology Session on the Great Green Wall}

Your excellencies, I am pleased to announce that between now and 2025, the World Bank Group will invest more than $\$ 5$ billion to improve livelihoods and restore degradation in the Sahel, Lake Chad, and Horn of Africa regions.

This investment, a major contribution to the Great Green Wall, comes at a crucial time. It will help improve livelihoods as countries recover from COVID-19 while also dealing with the impact of both biodiversity loss and climate change on their people and economies.

It includes interventions in agriculture, water, community development, food security, resilient infrastructure, landscape restoration, and renewable energy.

Working closely with many partners, PROGREEN, our global fund dedicated to boosting countries' efforts to address landscape degradation, will focus $\$ 14.5$ million on projects in Burkina Faso, Chad, Mali, Mauritania, and Niger.

The Sahel region, in particular, is one of the most vulnerable to desertification and land degradation.

Temperature increases are projected to be 1.5 times faster than the global average; 80 percent of farmlands are degraded; and about 30 million people are food insecure (FAO, 2019);

COVID-19 is exacerbating poverty levels. Extreme poverty rates in the Sahel are expected to increase for the first time in decades, by 1.5 percentage point on average in 2020. This translates into more than 1 million additional extreme poor in the Sahel region.

Investing in restoring the Sahel's landscapes is crucial to help mitigate these trends.

The World Bank's Sahel and West Africa Program (SAWAP), which began in 2012, has helped countries in the region to increase soil productivity and improve food security, bringing greater stability to people's lives. In countries from Senegal to Djibouti:

The program reached more than 19 million people and placed more than 1.6 million hectares of land under sustainable land management. 
For example, in Ethiopia, our project restored land and addressed the root causes of land degradation, including tenure insecurity. Land certificates have been issued to more than 360,000 households, many headed by women and youth.

And investing in landscape restoration makes economic sense: for example, in Niger, for every US $\$ 1$ invested, there is a return of $\$ 6$.

Finally, we are committed to partnering with all of you to transform this region. Only together, can we break the vicious cycle of poverty and create a more equal and sustainable world. 